\title{
Survival time and differences between dementia with Lewy bodies and Alzheimer's disease following diagnosis: A meta-analysis of longitudinal studies
}

Christoph Mueller ${ }^{1,2 *}$, Pinar Soysal ${ }^{1,3 *}$, Arvid Rongve ${ }^{4,5}$, Ahmet Turan Isik ${ }^{6}$, Trevor Thompson 7 , Stefania Maggi ${ }^{8}$, Lee Smith ${ }^{9}$, Cristina Basso $^{10}$, Robert Stewart ${ }^{1,2}$, Clive Ballard ${ }^{1,11}$, John T. O’Brien ${ }^{12}$, Dag Aarsland ${ }^{1,13}$, Brendon Stubbs ${ }^{1,2 \#}$, Nicola Veronese ${ }^{8,10 \#}$

${ }^{1}$ King's College London, Institute of Psychiatry, Psychology and Neuroscience, London, UK

${ }^{2}$ South London and Maudsley NHS Foundation Trust, London, UK

${ }^{3}$ Department of Geriatric Medicine, Bezmialem Vakif University, Faculty of Medicine, Istanbul, Turkey

${ }^{4}$ University of Bergen, Department of Clinical Medicine, Bergen, Norway

${ }^{5}$ Department of research and innovation, Haugesund Hospital, Helse Fonna HF, Haugesund, Norway.

${ }^{6}$ Unit for Aging Brain and Dementia, Department of Geriatric Medicine, Faculty of Medicine, Dokuz Eylul University, Izmir, Turkey.

${ }^{7}$ Faculty of Education and Health, University of Greenwich, London, UK.

${ }^{8}$ National Research Council, Neuroscience Institute, Aging Branch, Padova, Italy

${ }^{9}$ The Cambridge Centre for Sport and Exercise Sciences, Anglia Ruskin University, Cambridge, United Kingdom.

${ }^{10}$ Azienda Zero, Veneto Region, Venice, Italy

11 University of Exeter Medical School, Exeter, United Kingdom

12 Department of Psychiatry, School of Clinical Medicine, University of Cambridge, Cambridge, UK

${ }^{13}$ Stavanger University Hospital, Stavanger, Norway

* joint first author; * joint senior author 
Corresponding author: Christoph Mueller, MD; King's College London, Institute of Psychiatry, Psychology and Neuroscience (IoPPN), De Crespigny Park, London, SE5 8AF, United Kingdom; email: christoph.mueller@kcl.ac.uk; phone: +44 2078480626

\section{Declarations of interest:}

RS has received research funding from Roche, Pfizer, Janssen, Lundbeck and In-SilicoBioscience. DA has received research support and/or honoraria from Astra-Zeneca, $\mathrm{H}$. Lundbeck, Novartis Pharmaceuticals and GE Health, and serves as paid consultant for $\mathrm{H}$. Lundbeck and Axovant. CB has received honoraria and grant funding from Acadia pharmaceuticals, Lundbeck, Takeda and Axovant pharmaceutical companies. CB leads the ADP investigators group. Honoraria from Lundbeck, Lilly, Otusaka and Orion pharmaceutical companies. JO'B has acted as a consultant for GE Healthcare, TauRx, Axon, Piramal and Lilly and has received grants from Avid (Lilly). CB has received honoraria and grant funding from Acadia pharmaceuticals Lundbeck, Takeda and Axovant pharmaceutical companies. Honoraria from Lundbeck, Lilly, Otusaka and Orion pharmaceutical companies.

\section{Funding:}

CM, DA and RS receive salary support from the National Institute for Health Research (NIHR) Biomedical Research Centre at South London and Maudsley NHS Foundation Trust and King's College London, and RS and JOB are NIHR Senior Investigators. BS is supported by Health Education England and the National Institute for Health Research HEE/NIHR ICA Programme Clinical Lectureship (ICA-CL-2017-03-001). The views expressed are those of the author(s) and not necessarily those of the NHS, the NIHR or the Department of Health and Social Care. 


\section{Abstract (197/200)}

Objective: To synthesize the evidence across longitudinal studies comparing survival in dementia with Lewy bodies (DLB) and Alzheimer's disease (AD).

Methods: We conducted a systematic review and meta-analysis of studies comparing survival in clinically diagnosed DLB to AD. Longitudinal cohort studies were identified through a systematic search of major electronic databases from inception to May 2018. A random effects meta-analysis was performed to calculate survival time and relative risk of death.

Results: Overall, 11 studies were identified including 22,952 patients with dementia: 2,029 with DLB (mean diagnosis age 76.3; 47\% female) compared with 20,923 with AD (mean diagnosis age 77.2; $65.1 \%$ female). Average survival time in DLB from diagnosis was 4.11 years (SD \pm 4.10 ) and in AD 5.66 (SD \pm 5.32$)$ years, equating to a $1.60(95 \% \mathrm{Cl}:-2.44$ to -0.77$)$ years shorter in DLB $(p<0.01)$. Relative risk of death was increased by 1.35 ( $95 \% \mathrm{Cl}: 1.17-1.55)$ in DLB compared to AD ( $p<0.01)$. Differences in survival were not explained by follow-up time, age at diagnosis, gender, or cognitive score.

Conclusions: There is consistent evidence for higher and earlier mortality in DLB compared to AD. This is important for all stakeholders and underlines the importance of expanding research into DLB.

Key words: Dementia; Lewy bodies; Alzheimer's disease; mortality 


\section{Introduction}

Dementia with Lewy bodies (DLB) is the second most common form of neurodegenerative dementia, accounting for up to a quarter of all diagnosed dementia cases (Vann Jones and O'Brien, 2014) and is estimated to be present in $1 \%$ of older adults (Ballard et al., 2013). Compared to Alzheimer's disease (AD), DLB has been reported to have a considerably poorer prognosis and is associated with higher caregiver burden, higher costs of care, as well as increased rates of admission to general hospitals and residential care (Mueller et al., 2017a; Mueller et al., 2018).

Survival in DLB has been a matter of considerable clinical and academic debate (Mueller et al., 2017a). Initial post-mortem studies suggested a rapid mortality with survival times of less than two years (McKeith et al., 1992), but a later meta-analysis of neuropathologically confirmed cases of DLB published over 20 years ago suggested a longer mean survival time after diagnosis of 6.1 years (Cercy and Bylsma, 1997). Autopsy studies, which have provided most of the initial evidence, are prone to recruit biased cohorts, as post-mortems are usually carried out in selected samples of younger patients with uncertain diagnoses and atypical features (Walker et al., 2000). The advent of operationalized clinical criteria for DLB diagnosis (McKeith et al., 1996) paved the way for larger scale cohort studies to better understand prognosis and survival. Greater awareness amongst clinicians, further revisions of the diagnostic criteria (McKeith et al., 2017), the inclusion of DLB in the Diagnostic and Statistical Manual of Mental Disorders, Fifth Edition (DSM-5) (American Psychiatric Association, 2013), and the increased use of naturalistic data from electronic health records (Price et al., 2017) has led to an expanding number of publications on survival in DLB. The majority of observational studies, but not all, report shorter survival in DLB than AD (Mueller et al., 2017a). However, to the best of our knowledge, no systematic review or meta-analysis has synthesised this growing body of knowledge to describe and compare survival times from diagnosis. 
Given the importance of understanding the prognosis of the DLB for patients, their families and service planners, we conducted a systematic review and meta-analysis of observational studies to determine survival times from diagnosis and differences between DLB and AD and relative risk of mortality (primary aim) and assessed via meta-regression which factors might account for these differences (secondary aim). 


\section{Methods}

This systematic review was conducted according to the Strengthening the Reporting of Observational Studies in Epidemiology [STROBE] criteria and the recommendations in the Preferred Reporting Items for Systematic Reviews and Meta-Analyses [PRISMA] statement (Liberati et al., 2009; Wells G et al., 2012).

\section{Search strategy}

Two investigators (PS, NV) independently searched major databases (Pubmed, Medline, Scopus, Embase) without language restrictions, from inception until 01 ${ }^{\text {st }}$ May 2018. In Pubmed, the following controlled vocabulary terms and keywords were considered: (dementia lewy body or Lewy body OR Lewy bodies OR Lewy OR DLB OR LBD) and (mortality or death or survival). Similar searches were run in the other databases. Any inconsistencies were resolved by consensus with a third Author (CM). The reference lists of the articles included in the analysis were hand-searched to identify additional, potentially relevant publications. Conference abstracts were also considered. Authors were contacted at least two times in 1 month for obtaining additional information if needed.

\section{Study selection}

Two authors selected longitudinal cohort studies that reported survival time from dementia diagnosis (expressed in years) or in equivalents (e.g. months) in studies comparing people with DLB and $A D$.

\section{Inclusion/exclusion criteria}

We only considered studies that: (1) had a baseline and follow-up evaluation; (2) included patients with DLB, accepting all diagnostic criteria available (3) included a control group having a diagnosis of $A D$ (accepting all diagnostic criteria available) (4) reported data on survival/mortality parameters, 
expressed in years (from diagnosis of these conditions to death). Studies were excluded if they: (1) did not include patients with DLB; (2) conducted in vitro and on animal models; (3) were conducted in selected samples of autopsy cases; (4) evaluated co-morbid AD pathology in patients with DLB; (5) compared $A D$ to the Lewy body variant of $A D$, or (6) were reviews, book chapters and single case reports.

\section{Data extraction}

Two authors (PS, NV) independently extracted data from the selected studies in a standardized Microsoft Excel spreadsheet. Any disagreement was resolved with a third author (BS). The following information was extracted: 1) characteristics of the study population (e.g. sample size, demographics, setting, country in which the study was performed); 2) mean age, mean education year, percentage of females and baseline mean mini-mental state examination (MMSE) at the diagnosis; 3) diagnostic criteria of DLB and AD; 4) average age at diagnosis; 5) all data about survival. We planned to extract additional data (e.g. those regarding neuropsychiatric symptoms, disability, average age at the onset of symptoms), but since they were present in less than 4 studies (the minimum for running a meta-regression analysis), we did not include these data.

\section{Assessment of study quality}

Two independent reviewers (PS, NV) assessed the quality of studies, with a third available to resolve any discrepancies (BS). The Newcastle-Ottawa Scale (NOS) was used to assess study quality, which assigns a maximum of 9 points based on three quality parameters: selection, comparability, and outcome (Luchini, 2017; Wells G et al., 2012). Higher scores indicate better methodological quality.

\section{Outcomes}

The primary outcomes were survival data including mean survival time from diagnosis to death in DLB and $A D$. If expressed in other forms (e.g. median survival time, interquartile range survival time) 
these estimates were transformed in means and standard deviations (SDs). If the SD was not reported and was not possible to calculate from the data available in the full-text, a pooled SD was calculated, in agreement with the Cochrane guidelines (Higgins and Green, 2008). We further estimated the risk of death during the follow-up period between DLB and AD groups and performed meta-regression analyses to test whether differences in mean age and MMSE at diagnosis, follow-up time and percentage of females explained outcome differences between the studied cohorts.

\section{Statistical analysis}

The meta-analysis was performed using the Comprehensive Meta-Analysis 2.0 (CMA) software.

The difference, in mean, of the years survived in DLB group and in the AD group was reported through a mean difference (MD) with the correspondent 95\% confidence intervals (Cls). The random effects model was used to account for anticipated between-study heterogeneity (DerSimonian and Laird, 1986). This was assessed using the Chi-squared and I-squared statistics, assuming that a $p<0.10$ for the former and a value $\geq 50 \%$ for the latter were indications of significant heterogeneity (Higgins and Thompson, 2002). For the primary outcome, whenever significant heterogeneity existed and $\geq 4$ studies were available, a meta-regression analysis was performed examining the following pre-specified moderators: continent (categorized as Europe vs. America/Oceania); criteria used for DLB diagnosis (McKeith, 1992; McKeith, 1996; McKeith, 2005 or DSM-IV); year of publication (2000-2006, 2007-2012; 2013-2018); follow-up years (as continuous). Publication bias was assessed by visually inspecting funnel plots and using the Egger bias test (Egger et al., 1997). Finally, to account for publication bias, we used the trim-and-fill method, which adjusts for the potential effect of unpublished (imputed) studies (Duval and Tweedie, 2000). 


\section{Results}

The search identified 2,371 non-duplicated potentially eligible studies. After excluding 2,316 papers at title and abstract review, 55 full-text articles were examined, 11 of which (Bostrom et al., 2009; Connors et al., 2016; Garcia-Ptacek et al., 2016; Koedam et al., 2008; Magierski et al., 2010; Mueller et al., 2018; Oesterhus et al., 2014; Price et al., 2017; Stubendorff et al., 2011; Walker et al., 2000; Williams et al., 2006) were finally included in the systematic review and meta-analysis (Figure 1). Additional or updated information was kindly provided by the authors of three of the studies (Garcia-Ptacek et al., 2016; Mueller et al., 2018; Oesterhus et al., 2014).

\section{General characteristics}

The 11 studies followed-up a total of 22,952 patients with dementia $(2,029$ with DLB compared with 20,923 with AD) for a median of 5.02 years (Table 1). Nine studies were conducted in Europe (10; $=81.8 \%)$. The quality of the studies was generally sufficient (median NOS=7, range: $4-9$ ) and the most common potential source of bias was short follow-up periods and limited inclusion of possible confounders in the final analyses (see Supplementary Table 1).

As reported in Table 1, the criteria suggested by McKeith, 2005 (McKeith et al., 2005) were the most commonly used for the diagnosis of DLB (4 studies; $=36.3 \%$ ). The 2,029 participants with DLB had a mean age of $76.3(\mathrm{SD} \pm 7.0)$ years at the diagnosis and they were more frequently males $(52.6 \%)$. They had a mean MMSE score of $21.1( \pm 5.1)$ at diagnosis. Of the comparison group with AD $(\mathrm{N}=20,923)$ the mean age was $77.2( \pm 8.0)$ years, most were female $(65.0 \%)$ and mean MMSE score at diagnosis was $20.2( \pm 4.9)$.

Overall, patients with DLB were younger at the time of diagnosis at a level close to statistical significance $(p=0.08)$ than patients with $A D$, and a higher proportion were male $(p<0.01)$. Mean 
MMSE at diagnosis was slightly higher in patients with DLB, but this difference was not statistically significant $(p=0.11)$.

\section{Differences in survival years between DLB and AD}

Figure 2 summarizes the differences in survival years between DLB and AD cohorts. Of the 11 included studies, 7 reported significantly shorter survival in DLB than in AD, while the other 4 studies did not detect any statistically significant difference. Mean survival time after diagnosis was 4.11 $( \pm 4.10)$ years in people with DLB compared to $5.66( \pm 5.32)$ years in patients with AD. Hence survival was 1.60 years shorter in patients with DLB than in patients with $\mathrm{AD}(95 \% \mathrm{Cl}:-2.44$ to -0.77 years; $p<0.01)$, although between-study heterogeneity was high $\left(I^{2}=99 \%\right)$. The Egger's test did not indicate significant publication bias (Egger's test: $-2.61 \pm 2.59 ; \mathrm{p}=0.33$ ) and the trim and fill analysis did not meaningfully alter our findings. The fail-safe number for this outcome was high, needing 917 studies to nullify this finding. For those who died, the mean age at death was $80.8( \pm 7.0)$ for DLB and 83.7 $( \pm 7.2)$ for $A D(p=0.01)$.

Seven studies (Bostrom et al., 2009; Connors et al., 2016; Garcia-Ptacek et al., 2016; Koedam et al., 2008; Mueller et al., 2018; Oesterhus et al., 2014; Price et al., 2017) reported on the percentages of patients who died in the follow-up period. As shown in Figure 3, in the DLB cohort 780/1,838 (42.4\%) patients died during follow-up compared to $6,704 / 20,446$ (32.8\%) in the AD cohort. These estimates indicate a significantly higher risk of mortality in people with DLB compared to AD (relative risk $\left.=1.35 ; 95 \% \mathrm{Cl}: 1.17-1.55 ; \mathrm{p}<0.01 ; \mathrm{I}^{2}=80 \%\right)$. This outcome was also not apparently influenced by publication bias (Egger's test: $-0.20 \pm 2.05 ; p=0.92$ ) and the fail-safe number was 162 .

\section{Meta-regression and sensitivity analyses}

Since our primary outcome had a high heterogeneity $\left(I^{2}=99 \%\right)$, we investigated potential factors underpinning this using meta-regression and sensitivity analyses. Supplementary Table 2 shows the 
data on survival years stratified by continent, DLB diagnostic criteria applied (see Supplementary Table 3) and period of publication. Higher survival differences were observed in studies from outside Europe, and lower differences in older studies, but no significant interaction by stratum ( $p>0.05)$ was detected in any of the three categories.

Meta-regression analyses reported in Supplementary Table 4 further demonstrate that none of the available moderators (i.e. follow-up period, differences in mean age, in mean MMSE, or in percentage of females) explained differences in survival time between AD and DLB. 


\section{Discussion}

This meta-analysis of 11 longitudinal studies including more than 2,000 people with a clinical diagnosis of DLB demonstrated that patients with DLB have a significantly shorter survival from dementia diagnosis than patients with AD. Survival time was almost 20 months shorter in patients with DLB and their average survival time was 4.1 years. Relative risk of death was 1.35 higher in DLB compared to $A D$, and although no significant difference was detected in age at diagnosis, patients with DLB had a significant lower age at death. Neither gender difference, age at diagnosis, nor MMSE scores explained differences in survival time between DLB and AD.

Dementia is associated with a shortened life expectancy (Brodaty et al., 2012) and is increasingly recognised as a progressive, life-limiting condition without curative treatments, leading to a growing focus on advanced care planning (Perera et al., 2016; van der Steen et al., 2014). With the expected rise in people affected with dementia (Prince et al., 2013), giving indicators for prognosis, specifically survival, is of considerable interest both for patients, their families, as well as providers of health and social care services, with the aim to enable suitable support through the various stages of the illness (Todd et al., 2013). Several risk factors for mortality have been evaluated in patients with Alzheimer's disease and all-cause dementia (Brodaty et al., 2012; Todd et al., 2013) but only recently there has been enquiry into non-Alzheimer's dementias such as DLB. DLB has been found to be associated with accelerated cognitive decline, higher rates of hospitalisation and residential care, higher health care costs and lower quality of life (Mueller et al., 2017a; Mueller et al., 2018). Our results demonstrate that survival in DLB in clinically diagnosed samples is not as poor as expected from early autopsy studies (McKeith et al., 1992), although is significantly lower than in patients with AD. 
Although the available data only allows a coarse comparison, demographic characteristics and MMSE scores in our AD cohort (age at diagnosis 77 years; $65 \%$ female; mean MMSE 20 ) were similar to what is reported in larger samples of patients with Alzheimer's disease. For instance the data with $A D$ are broadly comparable with data from more than 26,000 patients diagnosed in Swedish memory clinics (age at diagnosis 80 years; 62\% female; mean MMSE 21) (Cermakova et al., 2017) suggesting representability of our sample.

A number of factors might explain the increased mortality risk in DLB compared to AD. Previous literature suggested that male gender could be identified as risk factor for mortality in dementia (Brodaty et al., 2012). Although this has not been replicated in all prevalence studies (Vann Jones and O'Brien, 2014), DLB has been associated with a male preponderance both in autopsy studies (Klatka et al., 1996) and clinical samples (Kane et al., 2018). Our data confirms the latter by demonstrating a significantly higher percentage of males on meta-analysis of DLB cohorts. However, when compared to $A D$ group, our meta-regression analysis did not suggest a role of differences in gender between the groups in explaining shorter time survival observed in DLB compared to AD patients. We can argue that, in agreement with the literature reporting a higher risk of death in older male subjects compared to females (Xu et al., 2010), also DLB males die more frequently than women, but this factor is not significant in explaining the differences in survival time between DLB and AD.

Although the difference only amounted to a trend $(p<0.1)$, DLB patients were also diagnosed at a slightly younger age. With age not explaining survival differences on meta-regression, despite being as strong risk factor for mortality (Todd et al., 2013), patients with DLB might be at a risk of an higher loss of life expectancy compared to those with other forms of dementia. This concurs with one Norwegian study finding that patients with DLB had a higher standardized mortality ratio compared to the general population than patients with $A D(2.6$ vs. 1.5) (Oesterhus et al., 2014) and is underlined by a significantly younger age of death in DLB than AD ( 81 vs. 84 years). 
Dementia disease severity can be assessed from a global, functional or cognitive perspective. The only measure available for the included studies was MMSE, which is not consistently associated with mortality risk in dementia (Todd et al., 2013) and might be too coarse an instrument to assess severity in DLB (Mueller et al., 2018). On meta-analysis we did not find differences in MMSE at baseline between DLB and AD cohorts, underlining the need for more in-depth testing and description of domains of cognitive decline between the conditions.

Although we cannot directly infer this from our data, other features of DLB and associated synucleinopathies, as motor, neuropsychiatric or autonomic symptoms, might contribute to the increased mortality risk. In patients with Alzheimer's disease, Parkinson-related symptoms as extrapyramidal signs, gait and postural instabilities and falls are related to increased mortality (Larson et al., 2004; Stern et al., 1997). Orthostatic hypotension is a specific risk factor for falls in patients with dementia (Allan et al., 2009) and is a predictor of mortality in DLB (Stubendorff et al., 2012). In addition to orthostatic hypotension, the effects of cardiovascular autonomic dysfunction, including neurocardiovascular instability, carotid sinus syndrome and abnormal sinus bradyarrhythmia, may cause a decrease in blood pressure negatively affect disease progression and survival of patients with DLB (Fanciulli et al., 2013; Kenny et al., 2002; Kenny et al., 2004). It is further possible that the neurodegenerative process in the synucleinopathy DLB is more rapid than in Alzheimer's disease, and a cell-to-cell alpha-synuclein spread has been hypothesized (George et al., 2013). Further AD-like pathological changes such as tau-inclusions and beta-amyloid are also likely to be present to some degree in DLB, and synergistic interactions between the three proteins have been suggested yielding a worse prognosis (Irwin et al., 2013).

Neuropsychiatric symptoms are more common in DLB than AD (Mueller et al., 2018), and in patients diagnosed with dementia these are independently associated with mortality, in particular the DLB core feature of visual hallucinations and the supportive feature of depression (Mehta et al., 2003; Okura et al., 2011; Scarmeas et al., 2005). Fluctuating cognition is a feature common to both DLB 
and delirium (Gore et al., 2015). As delirium frequently occurs in the months and weeks prior to a DLB diagnosis being established a delirium onset type of DLB has been postulated, whereby clinical misclassification being an alternative explanation (FitzGerald et al., 2018; McKeith et al., 2016; Morandi et al., 2017). Delirium is associated with increased mortality in older adults (Eeles et al., 2010) and this hazard might be increased in people diagnosed with delirium in the absence of a prior diagnosis of dementia, typical for DLB (Ward et al., 2015).

More than these features themselves, mortality risk in DLB may be further increased because of the medications prescribed to address them. The known increased mortality risk related to antipsychotic prescribing (e.g. for hallucinations or delirium) in people with dementia (Tampi et al., 2016) may be further amplified in those with DLB due to the pathognomonic feature of neuroleptic sensitivity (McKeith et al., 2005). However, although the majority of included studies report a higher proportion of these medications prescribed in DLB, antipsychotic prescription didn't emerge as significant modifier of survival differences in one study (Price et al., 2017). Although only demonstrated in Alzheimer's disease (Mueller et al., 2017b) and probably lower than antipsychotic risks (Maust et al., 2015), prescription of antidepressants in dementia might be associated with an increased mortality risk in patients with dementia.

Lastly, survival benefits of acetylcholinesterase inhibitors are well-demonstrated in AD (Mueller et al., 2017c) and these medications are in DLB associated with later transition to residential care and lower health care costs (Mueller et al., 2017a). Although no head-to-head comparisons are available, two studies reported level of antidementia drug use to be at a similar level in both cohorts (Price et al., 2017; Stubendorff et al., 2011) indicating that neither cohort is deprived of the benefits of these medications. 
Limitations:

Although our findings provide clinicians with helpful pointers to discuss prognosis with patients and carers, several caveats in assessing survival in patients with dementia need to be acknowledged.

First, we collated reported survival from the time of dementia diagnosis, as this is the point in time when questions about prognosis often arise. This is an imprecise timepoint as it depends on various patient, physician and service related factors, as cultural background, readiness to refer to secondary service, or availability of diagnostic services which might change over time (Todd et al., 2013). Inaccuracies arise in particular in DLB since caregivers report that the diagnosis is established after more than one year in half of the cases, and more than three quarters of cases receiving a different diagnosis initially (Galvin et al., 2010). However, this appears superior to symptom onset, as this is determined by recall bias, and variations in ability and threshold to recognize symptoms (Brodaty et al., 2012).

Second, the majority of studies did not neuropathologically confirm the dementia subtype diagnosis. However, although not as accurate as neuropathologically confirmed diagnoses, the clinical diagnoses applied in the included studies are more likely to reflect the reality of day-to-day practice. Diagnostic criteria have evolved since the first consensus guideline were established in 1996 (McKeith et al., 1996), with the 2005 revision (McKeith et al., 2005) increasing detection by one quarter (Aarsland et al., 2008). A recent meta-analysis (Rizzo et al., 2018) demonstrated that the diagnostic criteria have become more sensitive, but less specific, over time, which appears desirable given that DLB remains underdiagnosed in clinical practice (Kane et al., 2018).

A third limitation of our study is high heterogeneity, which is common in meta analyses of observational data. We attempted to address this by utilizing a random effects meta-analysis and through meta-regression analyses. However, we were unable to explain large portions of the variability we encountered. To further reduce heterogeneity, we only included studies which followed newly-diagnosed patients and excluded prevalence studies or studies solely including patients on the basis of available autopsy samples. Heterogeneity was not explained by the 
continent where the study was conducted, the diagnostic criteria used for DLB, the time period of publication, follow-up time available or patient characteristics. The most important potential explanation of heterogeneity may be the above-mentioned variation in presentation in the patient group itself, as well as variations in diagnostic practice, both regionally and over time (Kane et al., 2018; McKeith et al., 2016; Rizzo et al., 2018). One scenario is the so-called Lewy-body variant of Alzheimer's disease, which relies on the presence of neuropathological criteria for $A D$ and the additional presence of Lewy bodies. Under these conditions clinicians often do not make a diagnosis of DLB (McKeith et al., 2016; Thomas et al., 2018). However, when survival between the Lewy-body variant of $A D$ was compared with pure AD in several post-mortem studies (Chung et al., 2015; Lopez et al., 2000; Olichney et al., 1998), only one out of four studies (Olichney et al., 1998) reported worse survival of Lewy-body variant AD. It has been postulated that Lewy-body pathology might be a feature of late-stage Alzheimer's disease, as $45 \%$ of 22 neuropathologically confirmed cases of AD had co-existing Lewy bodies (Toledo et al., 2013). In contrast, studies evaluating the other scenario of mixed pathologies, the presence of AD pathology in patients with clinically diagnosed (Bostrom et al., 2009; Graff-Radford et al., 2016; Lemstra et al., 2017) and autopsy confirmed (Irwin et al., 2017; Jellinger et al., 2007) DLB have consistently demonstrated that co-morbid AD pathology increases mortality risk. We measured heterogeneity of the effect sizes using the 12 statistic as recommended by the Cochrane hand book (REF). However, it is important to also consider that the 12 metric may have some limitations when there are under than 20 studies (Langan et al., 2015).

Fourth, data available only allowed comparison of DLB to AD, with survival time for AD (5.7 years) being within the range previously reported (3.2 to 6.6 years) (Todd et al., 2013). Despite AD being the far most common type, future studies could attempt to elucidate survival differences in other dementia-causing disorders.

Fifth, we didn't have sufficient information to include ApoE4 status into the meta-analysis. However, a recent study in Alzheimer's disease has not implicated ApoE4 in survival (Rhodius-Meester et al., 2018) and the one included study (Williams et al., 2006) applying ApoE4 as a potential effector of 
mortality differences between $A D$ and DLB only detected a statistically significant effect from disease onset, not diagnosis, underlining its role as risk factor.

Lastly, changes in practice over time might affect survival, which could have improved over the studied period through greater awareness of public health measures (Livingston et al., 2017) and the availability of cholinesterase inhibitors which have been associated with survival benefits (Mueller et al., 2017c). However, period of study did not emerge as a moderator of the observed association on meta-regression.

\section{Conclusions:}

Survival time after diagnosis of DLB is of growing clinical and research interest. A review conducted eight years ago (Brodaty et al., 2012) included less than 200 cases of DLB, and we are now able to report more than ten times the combined sample size. Although heterogeneity is pronounced in mortality and Lewy body disorder research, our findings suggest that patients diagnosed with DLB have shorter survival from dementia diagnosis than patients with AD. A mean survival time of 4.1 years was concluded from this review, but mean survival times from diagnosis in the included studies ranged from 1.9 to 6.3 years, so there is clearly substantial heterogeneity which limits what can be reasonably communicated to individuals at this stage. Higher mortality suggests a higher likelihood of morbidity and dependency, and while the demonstrating a shorter survival in DLB compared to $A D$ is important for patients, their families and policy makers, important next steps are examining how this reduced life expectancy determines time spent at different levels of morbidity and the identification of specific risk factors of early mortality in this under-researched population.

\section{Acknowledgements}

The authors would thank for their contribution to the work: Sara Garcia-Ptacek, Karolinska Institutet, Stockholm, Sweden; and Michael Connors, Dementia Centre for Research Collaboration, UNSW Sydney. 


\section{Appendix A. Supplementary data}

Supplementary material related to this article can be found, in the online version, at doi:https://doi.org/10.1016/j.arr.2019.01.005. 


\section{References:}

Aarsland, D., Rongve, A., Nore, S.P., Skogseth, R., Skulstad, S., Ehrt, U., Hoprekstad, D., Ballard, C., 2008. Frequency and case identification of dementia with Lewy bodies using the revised consensus criteria. Dement Geriatr Cogn Disord 26, 445-452.

Allan, L.M., Ballard, C.G., Rowan, E.N., Kenny, R.A., 2009. Incidence and prediction of falls in dementia: a prospective study in older people. PLoS One 4, e5521.

American Psychiatric Association, 2013. Diagnostic and statistical manual of mental disorders DSM-5. , 5th edn. ed. American Psychiatric Association, Washington, DC.

Ballard, C., Aarsland, D., Francis, P., Corbett, A., 2013. Neuropsychiatric symptoms in patients with dementias associated with cortical Lewy bodies: pathophysiology, clinical features, and pharmacological management. Drugs Aging 30, 603-611.

Bostrom, F., Hansson, O., Blennow, K., Gerhardsson, L., Lundh, T., Minthon, L., Zetterberg, H., Londos, E., 2009. Cerebrospinal fluid total tau is associated with shorter survival in dementia with Lewy bodies. Dement Geriatr Cogn Disord 28, 314-319.

Brodaty, H., Seeher, K., Gibson, L., 2012. Dementia time to death: a systematic literature review on survival time and years of life lost in people with dementia. Int Psychogeriatr 24, 1034-1045.

Cercy, S.P., Bylsma, F.W., 1997. Lewy bodies and progressive dementia: a critical review and meta-analysis. J Int Neuropsychol Soc 3, 179-194.

Cermakova, P., Nelson, M., Secnik, J., Garcia-Ptacek, S., Johnell, K., Fastbom, J., Kilander, L., Winblad, B., Eriksdotter, M., Religa, D., 2017. Living Alone with Alzheimer's Disease: Data from SveDem, the Swedish Dementia Registry. J Alzheimers Dis 58, 1265-1272.

Chung, E.J., Babulal, G.M., Monsell, S.E., Cairns, N.J., Roe, C.M., Morris, J.C., 2015. Clinical Features of Alzheimer Disease With and Without Lewy Bodies. JAMA Neurol 72, 789796.

Connors, M.H., Ames, D., Boundy, K., Clarnette, R., Kurrle, S., Mander, A., Ward, J., Woodward, M., Brodaty, H., 2016. Predictors of Mortality in Dementia: The PRIME Study. J Alzheimers Dis 52, 967-974.

DerSimonian, R., Laird, N., 1986. Meta-analysis in clinical trials. Controlled clinical trials 7, 177-188.

Duval, S., Tweedie, R., 2000. Trim and fill: A simple funnel-plot-based method of testing and adjusting for publication bias in meta-analysis. Biometrics 56, 455-463.

Eeles, E.M., Hubbard, R.E., White, S.V., O'Mahony, M.S., Savva, G.M., Bayer, A.J., 2010. Hospital use, institutionalisation and mortality associated with delirium. Age Ageing 39, 470-475.

Egger, M., Davey Smith, G., Schneider, M., Minder, C., 1997. Bias in meta-analysis detected by a simple, graphical test. BMJ (Clinical research ed.) 315, 629-634.

Fanciulli, A., Strano, S., Colosimo, C., Caltagirone, C., Spalletta, G., Pontieri, F.E., 2013. The potential prognostic role of cardiovascular autonomic failure in alphasynucleinopathies. Eur J Neurol 20, 231-235.

FitzGerald, J.M., Perera, G., Chang-Tave, A., Price, A., Rajkumar, A.P., Bhattarai, M., O'Brien, J.T., Ballard, C., Aarsland, D., Stewart, R., Mueller, C., 2018. The Incidence of Recorded Delirium Episodes Before and After Dementia Diagnosis: Differences Between Dementia With Lewy Bodies and Alzheimer's Disease. J Am Med Dir Assoc. 
Galvin, J.E., Duda, J.E., Kaufer, D.I., Lippa, C.F., Taylor, A., Zarit, S.H., 2010. Lewy body dementia: the caregiver experience of clinical care. Parkinsonism Relat Disord 16, 388-392.

Garcia-Ptacek, S., Kareholt, I., Cermakova, P., Rizzuto, D., Religa, D., Eriksdotter, M., 2016. Causes of Death According to Death Certificates in Individuals with Dementia: A Cohort from the Swedish Dementia Registry. J Am Geriatr Soc 64, e137-e142.

George, S., Rey, N.L., Reichenbach, N., Steiner, J.A., Brundin, P., 2013. alpha-Synuclein: the long distance runner. Brain Pathol 23, 350-357.

Gore, R.L., Vardy, E.R., O'Brien, J.T., 2015. Delirium and dementia with Lewy bodies: distinct diagnoses or part of the same spectrum? J Neurol Neurosurg Psychiatry 86, 50-59.

Graff-Radford, J., Lesnick, T.G., Boeve, B.F., Przybelski, S.A., Jones, D.T., Senjem, M.L., Gunter, J.L., Ferman, T.J., Knopman, D.S., Murray, M.E., Dickson, D.W., Sarro, L., Jack, C.R., Jr., Petersen, R.C., Kantarci, K., 2016. Predicting Survival in Dementia With Lewy Bodies With Hippocampal Volumetry. Mov Disord 31, 989-994.

Higgins, J.P.T., Green, S., 2008. Cochrane Handbook for Systematic Reviews of.

Higgins, J.P.T., Thompson, S.G., 2002. Quantifying heterogeneity in a meta-analysis. Statistics in medicine 21, 1539-1558.

Irwin, D.J., Grossman, M., Weintraub, D., Hurtig, H.I., Duda, J.E., Xie, S.X., Lee, E.B., Van Deerlin, V.M., Lopez, O.L., Kofler, J.K., Nelson, P.T., Jicha, G.A., Woltjer, R., Quinn, J.F., Kaye, J., Leverenz, J.B., Tsuang, D., Longfellow, K., Yearout, D., Kukull, W., Keene, C.D., Montine, T.J., Zabetian, C.P., Trojanowski, J.Q., 2017. Neuropathological and genetic correlates of survival and dementia onset in synucleinopathies: a retrospective analysis. Lancet Neurol 16, 55-65.

Irwin, D.J., Lee, V.M., Trojanowski, J.Q., 2013. Parkinson's disease dementia: convergence of alpha-synuclein, tau and amyloid-beta pathologies. Nat Rev Neurosci 14, 626-636.

Jellinger, K.A., Wenning, G.K., Seppi, K., 2007. Predictors of survival in dementia with lewy bodies and Parkinson dementia. Neurodegener Dis 4, 428-430.

Kane, J.P.M., Surendranathan, A., Bentley, A., Barker, S.A.H., Taylor, J.P., Thomas, A.J., Allan, L.M., McNally, R.J., James, P.W., McKeith, I.G., Burn, D.J., O'Brien, J.T., 2018. Clinical prevalence of Lewy body dementia. Alzheimers Res Ther 10, 19.

Kenny, R.A., Kalaria, R., Ballard, C., 2002. Neurocardiovascular instability in cognitive impairment and dementia. Ann N Y Acad Sci 977, 183-195.

Kenny, R.A., Shaw, F.E., O'Brien, J.T., Scheltens, P.H., Kalaria, R., Ballard, C., 2004. Carotid sinus syndrome is common in dementia with Lewy bodies and correlates with deep white matter lesions. J Neurol Neurosurg Psychiatry 75, 966-971.

Klatka, L.A., Louis, E.D., Schiffer, R.B., 1996. Psychiatric features in diffuse Lewy body disease: a clinicopathologic study using Alzheimer's disease and Parkinson's disease comparison groups. Neurology 47, 1148-1152.

Koedam, E.L., Pijnenburg, Y.A., Deeg, D.J., Baak, M.M., van der Vlies, A.E., Scheltens, P., van der Flier, W.M., 2008. Early-onset dementia is associated with higher mortality. Dement Geriatr Cogn Disord 26, 147-152.

Langan, D., Higgins, J.P., Simmonds, M., 2015. An empirical comparison of heterogeneity variance estimators in 12894 meta-analyses. Res Synth Methods 6, 195-205.

Larson, E.B., Shadlen, M.F., Wang, L., McCormick, W.C., Bowen, J.D., Teri, L., Kukull, W.A., 2004. Survival after initial diagnosis of Alzheimer disease. Ann Intern Med 140, 501509. 
Lemstra, A.W., de Beer, M.H., Teunissen, C.E., Schreuder, C., Scheltens, P., van der Flier, W.M., Sikkes, S.A., 2017. Concomitant AD pathology affects clinical manifestation and survival in dementia with Lewy bodies. J Neurol Neurosurg Psychiatry 88, 113118.

Liberati, A., Altman, D.G., Tetzlaff, J., Mulrow, C., Gotzsche, P.C., loannidis, J.P., Clarke, M., Devereaux, P.J., Kleijnen, J., Moher, D., 2009. The PRISMA statement for reporting systematic reviews and meta-analyses of studies that evaluate health care interventions: explanation and elaboration. PLoS Med 6, e1000100.

Livingston, G., Sommerlad, A., Orgeta, V., Costafreda, S.G., Huntley, J., Ames, D., Ballard, C., Banerjee, S., Burns, A., Cohen-Mansfield, J., Cooper, C., Fox, N., Gitlin, L.N., Howard, R., Kales, H.C., Larson, E.B., Ritchie, K., Rockwood, K., Sampson, E.L., Samus, Q., Schneider, L.S., Selbaek, G., Teri, L., Mukadam, N., 2017. Dementia prevention, intervention, and care. Lancet 390, 2673-2734.

Lopez, O.L., Wisniewski, S., Hamilton, R.L., Becker, J.T., Kaufer, D.I., DeKosky, S.T., 2000. Predictors of progression in patients with AD and Lewy bodies. Neurology 54, 17741779.

Luchini, C.S., Brendon; Solmi, Marco; Veronese, Nicola 2017. Assessing the quality of studies in meta-analyses: Advantages and limitations of the Newcastle Ottawa Scale World J Meta-Anal 5, 80-84.

Magierski, R., Kłoszewska, I., Sobów, T.M., 2010. The influence of vascular risk factors on the survival rate of patients with dementia with Lewy bodies and Alzheimer disease. Neurologia i Neurochirurgia Polska 44, 139-147.

Maust, D.T., Kim, H.M., Seyfried, L.S., Chiang, C., Kavanagh, J., Schneider, L.S., Kales, H.C., 2015. Antipsychotics, other psychotropics, and the risk of death in patients with dementia: number needed to harm. JAMA Psychiatry 72, 438-445.

McKeith, I., Taylor, J.P., Thomas, A., Donaghy, P., Kane, J., 2016. Revisiting DLB Diagnosis: A Consideration of Prodromal DLB and of the Diagnostic Overlap With Alzheimer Disease. J Geriatr Psychiatry Neurol 29, 249-253.

McKeith, I.G., Boeve, B.F., Dickson, D.W., Halliday, G., Taylor, J.P., Weintraub, D., Aarsland, D., Galvin, J., Attems, J., Ballard, C.G., Bayston, A., Beach, T.G., Blanc, F., Bohnen, N., Bonanni, L., Bras, J., Brundin, P., Burn, D., Chen-Plotkin, A., Duda, J.E., El-Agnaf, O., Feldman, H., Ferman, T.J., Ffytche, D., Fujishiro, H., Galasko, D., Goldman, J.G., Gomperts, S.N., Graff-Radford, N.R., Honig, L.S., Iranzo, A., Kantarci, K., Kaufer, D., Kukull, W., Lee, V.M.Y., Leverenz, J.B., Lewis, S., Lippa, C., Lunde, A., Masellis, M., Masliah, E., McLean, P., Mollenhauer, B., Montine, T.J., Moreno, E., Mori, E., Murray, M., O'Brien, J.T., Orimo, S., Postuma, R.B., Ramaswamy, S., Ross, O.A., Salmon, D.P., Singleton, A., Taylor, A., Thomas, A., Tiraboschi, P., Toledo, J.B., Trojanowski, J.Q., Tsuang, D., Walker, Z., Yamada, M., Kosaka, K., 2017. Diagnosis and management of dementia with Lewy bodies: Fourth consensus report of the DLB Consortium. Neurology 89, 88-100.

McKeith, I.G., Dickson, D.W., Lowe, J., Emre, M., O'Brien, J.T., Feldman, H., Cummings, J., Duda, J.E., Lippa, C., Perry, E.K., Aarsland, D., Arai, H., Ballard, C.G., Boeve, B., Burn, D.J., Costa, D., Del Ser, T., Dubois, B., Galasko, D., Gauthier, S., Goetz, C.G., GomezTortosa, E., Halliday, G., Hansen, L.A., Hardy, J., Iwatsubo, T., Kalaria, R.N., Kaufer, D., Kenny, R.A., Korczyn, A., Kosaka, K., Lee, V.M., Lees, A., Litvan, I., Londos, E., Lopez, O.L., Minoshima, S., Mizuno, Y., Molina, J.A., Mukaetova-Ladinska, E.B., Pasquier, F., Perry, R.H., Schulz, J.B., Trojanowski, J.Q., Yamada, M., Consortium on, D.L.B., 2005. 
Diagnosis and management of dementia with Lewy bodies: third report of the DLB Consortium. Neurology 65, 1863-1872.

McKeith, I.G., Galasko, D., Kosaka, K., Perry, E.K., Dickson, D.W., Hansen, L.A., Salmon, D.P., Lowe, J., Mirra, S.S., Byrne, E.J., Lennox, G., Quinn, N.P., Edwardson, J.A., Ince, P.G., Bergeron, C., Burns, A., Miller, B.L., Lovestone, S., Collerton, D., Jansen, E.N., Ballard, C., de Vos, R.A., Wilcock, G.K., Jellinger, K.A., Perry, R.H., 1996. Consensus guidelines for the clinical and pathologic diagnosis of dementia with Lewy bodies (DLB): report of the consortium on DLB international workshop. Neurology 47, 1113-1124.

McKeith, I.G., Perry, R.H., Fairbairn, A.F., Jabeen, S., Perry, E.K., 1992. Operational criteria for senile dementia of Lewy body type (SDLT). Psychol Med 22, 911-922.

Mehta, K.M., Yaffe, K., Langa, K.M., Sands, L., Whooley, M.A., Covinsky, K.E., 2003. Additive effects of cognitive function and depressive symptoms on mortality in elderly community-living adults. J Gerontol A Biol Sci Med Sci 58, M461-467.

Morandi, A., Davis, D., Bellelli, G., Arora, R.C., Caplan, G.A., Kamholz, B., Kolanowski, A., Fick, D.M., Kreisel, S., MacLullich, A., Meagher, D., Neufeld, K., Pandharipande, P.P., Richardson, S., Slooter, A.J., Taylor, J.P., Thomas, C., Tieges, Z., Teodorczuk, A., Voyer, P., Rudolph, J.L., 2017. The Diagnosis of Delirium Superimposed on Dementia: An Emerging Challenge. J Am Med Dir Assoc 18, 12-18.

Mueller, C., Ballard, C., Corbett, A., Aarsland, D., 2017a. The prognosis of dementia with Lewy bodies. Lancet Neurol 16, 390-398.

Mueller, C., Huntley, J., Stubbs, B., Sommerlad, A., Carvalho, A.F., Perera, G., Stewart, R., Veronese, N., 2017b. Associations of Neuropsychiatric Symptoms and Antidepressant Prescription with Survival in Alzheimer's Disease. J Am Med Dir Assoc 18, 1076-1081.

Mueller, C., Perera, G., Hayes, R.D., Shetty, H., Stewart, R., 2017c. Associations of acetylcholinesterase inhibitor treatment with reduced mortality in Alzheimer's disease: a retrospective survival analysis. Age Ageing, 1-7.

Mueller, C., Perera, G., Rajkumar, A., Bhattarai, M., Price, A., O'Brien, J., Ballard, C., Stewart, R., Aarsland, D., 2018. Hospitalization in people with dementia with Lewy bodies: Frequency, duration, and cost implications. Alzheimer's \& Dementia: Diagnosis, Assessment \& Disease Monitoring 10, 143-152.

Oesterhus, R., Soennesyn, H., Rongve, A., Ballard, C., Aarsland, D., Vossius, C., 2014. Longterm mortality in a cohort of home-dwelling elderly with mild Alzheimer's disease and Lewy body dementia. Dement Geriatr Cogn Disord 38, 161-169.

Okura, T., Plassman, B.L., Steffens, D.C., Llewellyn, D.J., Potter, G.G., Langa, K.M., 2011. Neuropsychiatric symptoms and the risk of institutionalization and death: the aging, demographics, and memory study. J Am Geriatr Soc 59, 473-481.

Olichney, J.M., Galasko, D., Salmon, D.P., Hofstetter, C.R., Hansen, L.A., Katzman, R., Thal, L.J., 1998. Cognitive decline is faster in Lewy body variant than in Alzheimer's disease. Neurology 51, 351-357.

Perera, G., Stewart, R., Higginson, I.J., Sleeman, K.E., 2016. Reporting of clinically diagnosed dementia on death certificates: retrospective cohort study. Age and ageing, afw077.

Price, A., Farooq, R., Yuan, J.M., Menon, V.B., Cardinal, R.N., O'Brien, J.T., 2017. Mortality in dementia with Lewy bodies compared with Alzheimer's dementia: a retrospective naturalistic cohort study. BMJ Open 7, e017504. 
Prince, M., Bryce, R., Albanese, E., Wimo, A., Ribeiro, W., Ferri, C.P., 2013. The global prevalence of dementia: a systematic review and metaanalysis. Alzheimers Dement 9, 63-75 e62.

Rhodius-Meester, H.F.M., Liedes, H., Koene, T., Lemstra, A.W., Teunissen, C.E., Barkhof, F., Scheltens, P., van Gils, M., Lotjonen, J., van der Flier, W.M., 2018. Disease-related determinants are associated with mortality in dementia due to Alzheimer's disease. Alzheimers Res Ther 10, 23.

Rizzo, G., Arcuti, S., Copetti, M., Alessandria, M., Savica, R., Fontana, A., Liguori, R., Logroscino, G., 2018. Accuracy of clinical diagnosis of dementia with Lewy bodies: a systematic review and meta-analysis. J Neurol Neurosurg Psychiatry 89, 358-366.

Scarmeas, N., Brandt, J., Albert, M., Hadjigeorgiou, G., Papadimitriou, A., Dubois, B., Sarazin, M., Devanand, D., Honig, L., Marder, K., Bell, K., Wegesin, D., Blacker, D., Stern, Y., 2005. Delusions and hallucinations are associated with worse outcome in Alzheimer disease. Arch Neurol 62, 1601-1608.

Stern, Y., Tang, M.X., Albert, M.S., Brandt, J., Jacobs, D.M., Bell, K., Marder, K., Sano, M., Devanand, D., Albert, S.M., Bylsma, F., Tsai, W.Y., 1997. Predicting time to nursing home care and death in individuals with Alzheimer disease. JAMA 277, 806-812.

Stubendorff, K., Aarsland, D., Minthon, L., Londos, E., 2012. The impact of autonomic dysfunction on survival in patients with dementia with Lewy bodies and Parkinson's disease with dementia. PLoS One 7, e45451.

Stubendorff, K., Hansson, O., Minthon, L., Londos, E., 2011. Differences in survival between patients with dementia with Lewy bodies and patients with Alzheimer's disease-measured from a fixed cognitive level. Dement Geriatr Cogn Disord 32, 408-416.

Tampi, R.R., Tampi, D.J., Balachandran, S., Srinivasan, S., 2016. Antipsychotic use in dementia: a systematic review of benefits and risks from meta-analyses. Ther Adv Chronic Dis 7, 229-245.

Thomas, A.J., Mahin-Babaei, F., Saidi, M., Lett, D., Taylor, J.P., Walker, L., Attems, J., 2018. Improving the identification of dementia with Lewy bodies in the context of an Alzheimer's-type dementia. Alzheimers Res Ther 10, 27.

Todd, S., Barr, S., Roberts, M., Passmore, A.P., 2013. Survival in dementia and predictors of mortality: a review. Int J Geriatr Psychiatry 28, 1109-1124.

Toledo, J.B., Cairns, N.J., Da, X., Chen, K., Carter, D., Fleisher, A., Householder, E., Ayutyanont, N., Roontiva, A., Bauer, R.J., Eisen, P., Shaw, L.M., Davatzikos, C., Weiner, M.W., Reiman, E.M., Morris, J.C., Trojanowski, J.Q., Alzheimer's Disease Neuroimaging, I., 2013. Clinical and multimodal biomarker correlates of ADNI neuropathological findings. Acta Neuropathol Commun 1, 65.

van der Steen, J.T., Radbruch, L., Hertogh, C.M., de Boer, M.E., Hughes, J.C., Larkin, P., Francke, A.L., Junger, S., Gove, D., Firth, P., Koopmans, R.T., Volicer, L., European Association for Palliative, C., 2014. White paper defining optimal palliative care in older people with dementia: a Delphi study and recommendations from the European Association for Palliative Care. Palliat Med 28, 197-209.

Vann Jones, S.A., O'Brien, J.T., 2014. The prevalence and incidence of dementia with Lewy bodies: a systematic review of population and clinical studies. Psychol Med 44,673683.

Walker, Z., Allen, R.L., Shergill, S., Mullan, E., Katona, C.L., 2000. Three years survival in patients with a clinical diagnosis of dementia with Lewy bodies. Int J Geriatr Psychiatry 15, 267-273. 
Ward, G., Perera, G., Stewart, R., 2015. Predictors of mortality for people aged over 65 years receiving mental health care for delirium in a South London Mental Health Trust, UK: a retrospective survival analysis. International journal of geriatric psychiatry 30,639 646.

Wells G, Shea B, O'Connell D, J Peterson, V Welch, M Losos, Tugwell., P., 2012. The Newcastle-Ottawa Scale (NOS) for assessing the quality if nonrandomized studies in meta-analyses. http//www.ohri.ca/programs/clinical epidemiology/oxford.asp.

Williams, M.M., Xiong, C., Morris, J.C., Galvin, J.E., 2006. Survival and mortality differences between dementia with Lewy bodies vs Alzheimer disease. Neurology 67, 19351941.

Xu, J., Kochanek, K.D., Murphy, S.L., Tejada-Vera, B., 2010. Deaths: final data for 2007. Natl Vital Stat Rep 58, 1-19. 


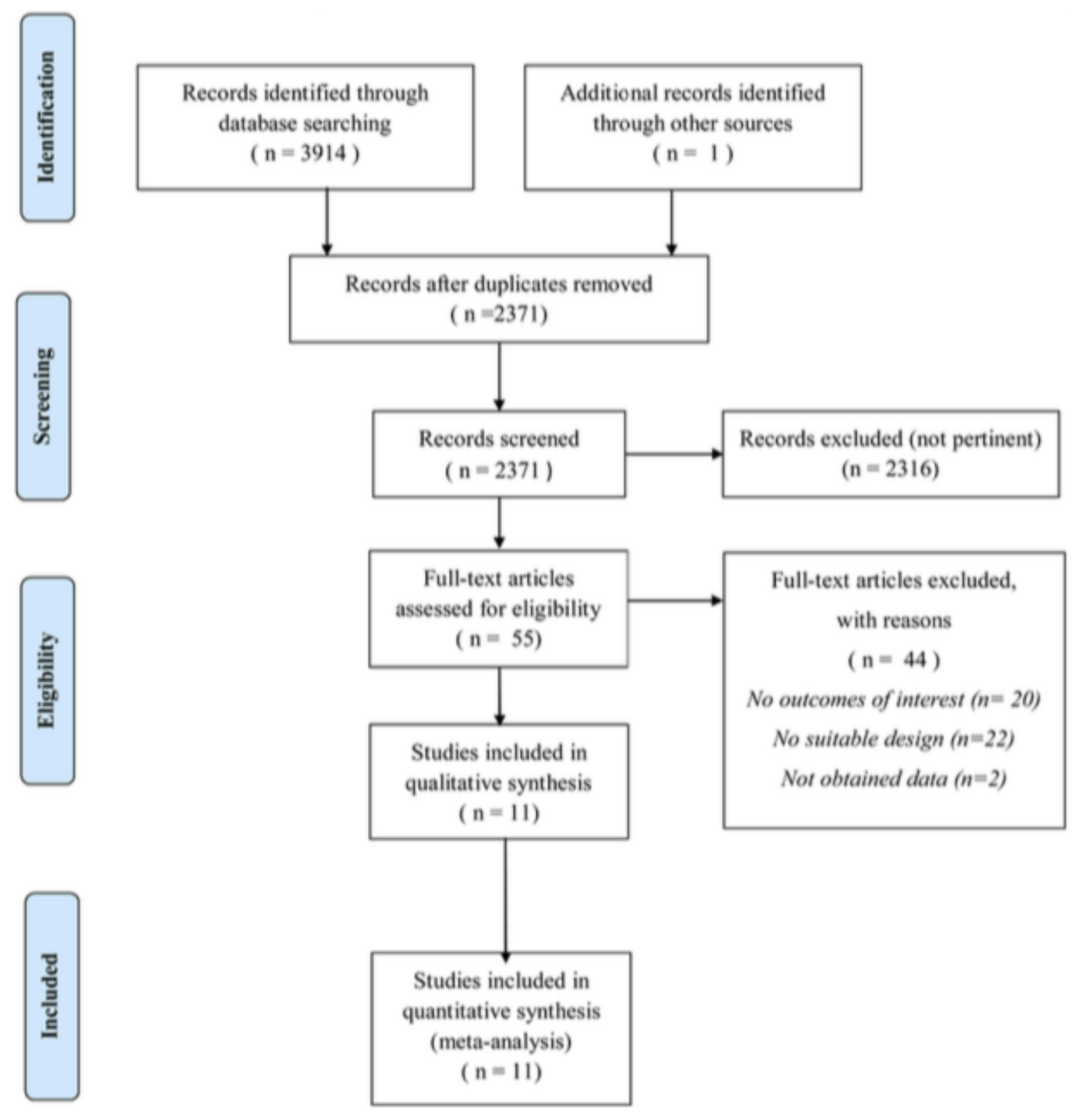

Fig. 1. PRISMA flow-chart. 


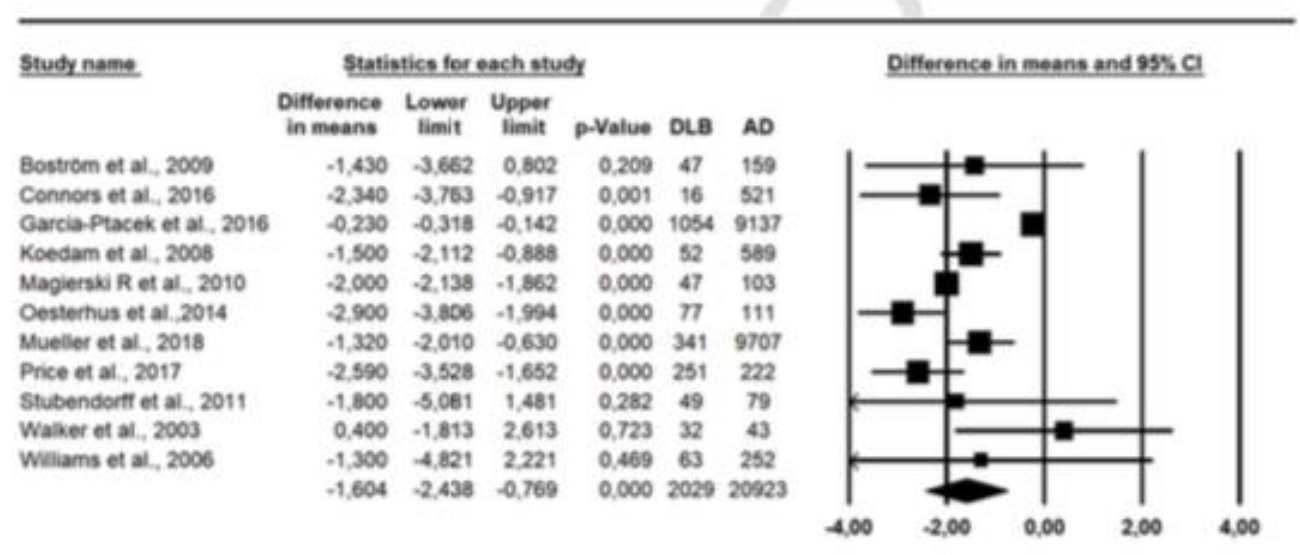

\section{DLB AD}

Fig. 2. Comparion of survival time from dementia diagnodis in DLB and AD.

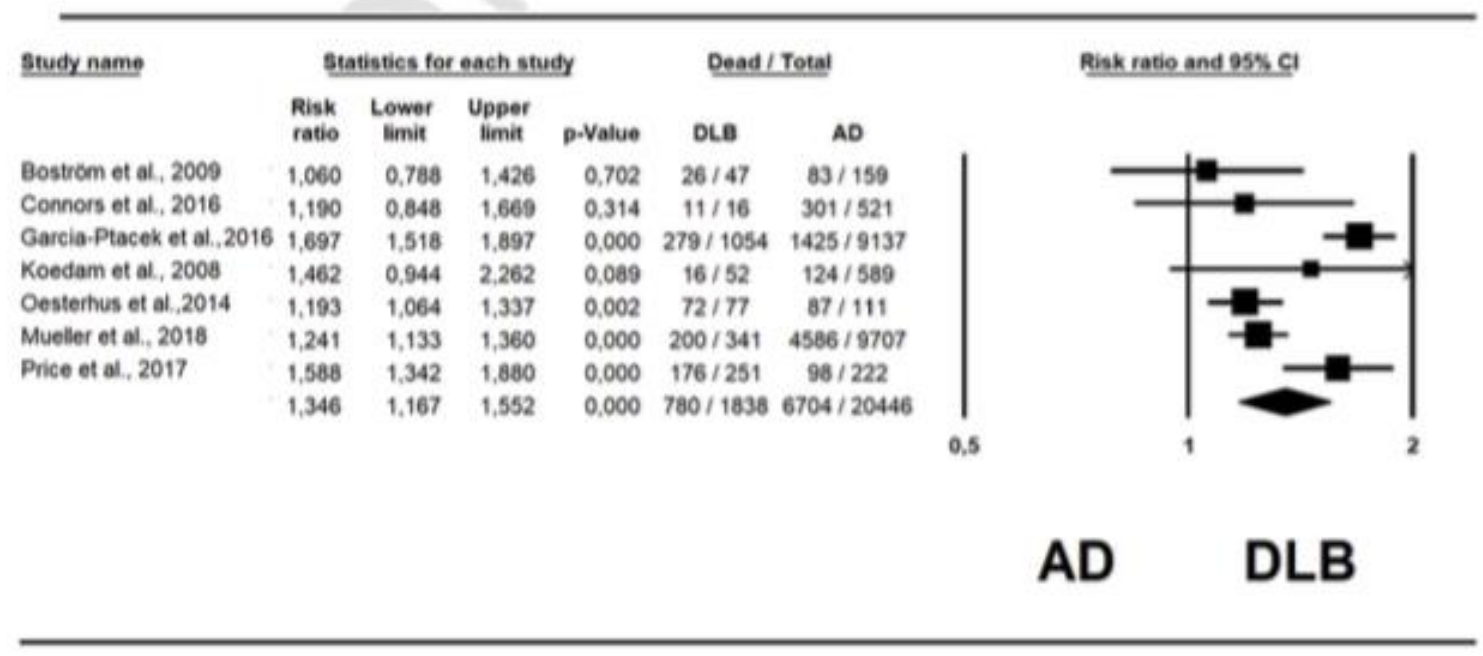

Fig. 3. Comparison of risk of death in DL.B and AD. 
Table 1

Descriptive characteristics of the studies included.

\begin{tabular}{|c|c|c|c|c|c|c|c|c|c|c|c|c|c|}
\hline & & & & DLB & & & & & $\mathrm{AD}$ & & 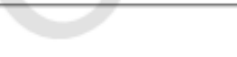 & & \\
\hline Author (year) & Country & $\begin{array}{l}\text { Follow-up } \\
\text { (years) }\end{array}$ & $\begin{array}{l}\text { Diagnostic } \\
\text { criteria }\end{array}$ & $\mathrm{N}$ & $\begin{array}{l}\text { Age at } \\
\text { diagnosis (SD) }\end{array}$ & $\begin{array}{l}\text { Survival from diagnosis to } \\
\text { death }(y ; S D)\end{array}$ & $\begin{array}{l}\text { Female } \\
\text { (\%) }\end{array}$ & $\begin{array}{l}\text { MMSE at } \\
\text { diagnosis } \\
\text { (SD) }\end{array}$ & $\mathrm{N}$ & $\begin{array}{l}\text { Age at } \\
\text { diagnodis } \\
\text { (SD) }\end{array}$ & $\begin{array}{l}\text { Survival from diagnosis } \\
\text { to death (y) }\end{array}$ & $\begin{array}{l}\text { Female } \\
\text { (\%) }\end{array}$ & $\begin{array}{l}\text { MMSE at } \\
\text { diagnosis } \\
\text { (SD) }\end{array}$ \\
\hline $\begin{array}{l}\text { Bostrom et al, } \\
2009\end{array}$ & Sweden & 7 & $\begin{array}{l}\text { Mckeith } \\
\text { criteria,2005 }\end{array}$ & 47 & & $5.59(5.7)$ & 46.8 & $\begin{array}{l}22.7 \\
(5.3)\end{array}$ & 159 & & $7.02(7.16)$ & 75.5 & $\begin{array}{l}20.2 \\
(4.9)\end{array}$ \\
\hline $\begin{array}{l}\text { Connors et al., } \\
2016\end{array}$ & Australia & 3 & DSMAV & 16 & $\begin{array}{l}75.1 \\
(5.7)\end{array}$ & $3.87(1.46)$ & 25 & $\begin{array}{l}23.8 \\
(4.2)\end{array}$ & 521 & $\begin{array}{l}76.7 \\
(7.9)\end{array}$ & $6.21(2.89)$ & 51.2 & $\begin{array}{l}21.1 \\
(5.3)\end{array}$ \\
\hline $\begin{array}{l}\text { Garcia-Ptacek et } \\
\text { al, 2016" }\end{array}$ & Sweden & 2,03 & $\begin{array}{l}\text { Mckeith } \\
\text { criteria,2005 }\end{array}$ & 1054 & $\begin{array}{l}76.52 \\
(7.06)\end{array}$ & $2.06(1.31)$ & 39.7 & $\begin{array}{l}21.41 \\
(5.04)\end{array}$ & 9137 & $\begin{array}{l}77.58 \\
(8.27)\end{array}$ & $\begin{array}{l}2.29 \\
(1.39)\end{array}$ & 65.2 & $\begin{array}{l}21.5 \\
(5.01)\end{array}$ \\
\hline $\begin{array}{l}\text { Koedam et al, } \\
2008\end{array}$ & Netherlands & 2,5 & $\begin{array}{l}\text { McKeith } \\
\text { criteria, } 1996\end{array}$ & 52 & $\begin{array}{l}75 \\
(7)\end{array}$ & $1.9(1.6)$ & 33 & $\begin{array}{l}22 \\
(5)\end{array}$ & 589 & $\begin{array}{l}71 \\
(10)\end{array}$ & $3.4(2.2)$ & 57 & $\begin{array}{l}20 \\
(5)\end{array}$ \\
\hline $\begin{array}{l}\text { Magierski et al, } \\
2010\end{array}$ & Poland & 8 & $\begin{array}{l}\text { McKeith } \\
\text { criteria,1996 }\end{array}$ & 47 & $\begin{array}{l}76.6 \\
(4.4)\end{array}$ & $\begin{array}{l}6.3 \\
(0.4)\end{array}$ & 70.2 & $\begin{array}{l}19.9 \\
(4)\end{array}$ & 103 & $\begin{array}{l}78.1 \\
(4.9)\end{array}$ & $\begin{array}{l}8.3 \\
(0.4)\end{array}$ & 68 & $\begin{array}{l}20.3 \\
(3.1)\end{array}$ \\
\hline Costartis exi, 2014 a & Nonway & 6,7 & $\begin{array}{l}\text { Mckeith } \\
\text { criteria,2005 }\end{array}$ & $\pi 7$ & $\begin{array}{l}76.6 \\
(7.3)\end{array}$ & 4.52 & 48.1 & $\begin{array}{l}23.3 \\
(3.2)\end{array}$ & 111 & $\begin{array}{l}75.6 \\
(7.4)\end{array}$ & 7.42 & 71.2 & $\begin{array}{l}23.7 \\
(2.3)\end{array}$ \\
\hline Maveler et a, 2018a & UK & 10 & $\begin{array}{l}\text { McKeith } \\
\text { criteria,2005 }\end{array}$ & 341 & $\begin{array}{l}78.6 \\
(9.5)\end{array}$ & 3.44 & 50.2 & $\begin{array}{l}19.5 \\
(6.4)\end{array}$ & 9707 & $\begin{array}{l}80.8 \\
(9.3)\end{array}$ & 4.76 & 65.34 & $\begin{array}{l}18.8 \\
(6.4)\end{array}$ \\
\hline Price et al, 2017 & UK & 8 & $\begin{array}{l}\text { McKeith } \\
\text { criteria,2005 }\end{array}$ & 251 & $\begin{array}{l}79.3 \\
(7.6)\end{array}$ & $4.40(2.63)$ & 51.4 & $\begin{array}{l}20.1 \\
(5.5)\end{array}$ & 222 & $\begin{array}{l}80.2 \\
(8.8)\end{array}$ & $6.99(7.05)$ & 62.6 & $\begin{array}{l}20.6 \\
(4.9)\end{array}$ \\
\hline $\begin{array}{l}\text { Stubendorff et al, } \\
2011\end{array}$ & Sweden & 5 & $\begin{array}{l}\text { McKeith } \\
\text { criteria, } 1996\end{array}$ & 49 & $\begin{array}{l}75.8 \\
\text { (6) }\end{array}$ & $4.7(\mathrm{SE}: 1.30)^{c}$ & 45 & $\begin{array}{l}22 \\
(8-29)\end{array}$ & 79 & $\begin{array}{l}76 \\
(6.0)\end{array}$ & 6.5 (SE: 1.03$)^{f}$ & 73 & $\begin{array}{l}21 \\
(6-29)\end{array}$ \\
\hline Walker et al,, 2000 & UK & 3 & $\begin{array}{l}\text { McKeith } \\
\text { criteria, } 1992\end{array}$ & 32 & $\begin{array}{l}75.8 \\
\text { (NA) }\end{array}$ & 3.5 (mean) & 71,8 & $\begin{array}{l}16.7 \\
(7.1)\end{array}$ & 43 & $\begin{array}{l}78.1 \\
\text { (NA) }\end{array}$ & 3.1 (mean) & 65.1 & $\begin{array}{l}15.8 \\
(7.6)\end{array}$ \\
\hline $\begin{array}{l}\text { Williams et al, } \\
2006\end{array}$ & USA & & $\begin{array}{l}\text { McKeith } \\
\text { criteria, } 1996\end{array}$ & 63 & $\begin{array}{l}73.5 \\
(8.7)\end{array}$ & 5.00 (SE: 1.54) & 40.3 & & 252 & $\begin{array}{l}77.8 \\
(9.5)\end{array}$ & 6.30 (SE: 0.81 ) & 62.3 & \\
\hline Total & & $\begin{array}{l}\text { Median }=5.02 \\
\text { (range: } 2-10 \text { ) }\end{array}$ & & 2029 & $\begin{array}{l}\text { Mean = } \\
76.3 \\
(7.03)\end{array}$ & & 47.4 & $\begin{array}{l}\text { Mean }= \\
21.1 \\
(4.7)\end{array}$ & 20,923 & $\begin{array}{l}\text { Mean = } \\
77.2 \\
(8.0)\end{array}$ & & 65.1 & $\begin{array}{l}\text { Mean = } \\
20.3 \\
(4.9)\end{array}$ \\
\hline
\end{tabular}

apdated data acquired from author.

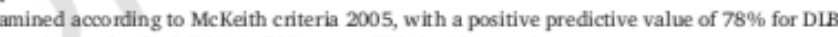

c Only available for patients who died (80\% in DLB group; $75 \%$ in AD group). 